\title{
Are Doctors Protected Enough During COVID-19? A Cross-Sectional Study of Physician Mortality Numbers and Characteristics in South Asia
}

\author{
Nadia Nazir Jatoi \\ Dow University of Health Sciences
}

Saniya Ahmad

Dow University of Health Sciences

\section{Emaad-ud din Sajid}

Dow University of Health Sciences

Syed Ali Farhan ( $\square$ syed_ali11@hotmail.com )

Dow University of Health Sciences https://orcid.org/0000-0003-0461-0060

\section{Kaneez Fatima}

Dow University of Health Sciences

\section{Syed Faisal Mahmood}

Aga Khan University Medical College Pakistan

\section{Research}

Keywords: COVID-19, Physician Mortality, South Asia

Posted Date: February 10th, 2021

DOI: https://doi.org/10.21203/rs.3.rs-215246/v1

License: @ (i) This work is licensed under a Creative Commons Attribution 4.0 International License. Read Full License 


\section{Abstract}

\section{Background:}

The highly contagious nature of the severe acute respiratory syndrome coronavirus 2 (SARS-CoV-2) places physicians in South Asia at a high risk of contracting the infection. Accordingly, we conducted this review to provide an up to date account of physician deaths in South Asia during the COVID-19 pandemic and to analyze and compare the different characteristics associated with physician mortality amongst the countries of the region.

\section{Study Design:}

Cross-Sectional Study

\section{Methodology:}

We performed a review study by using published news reports on the websites of news agencies from 9 selected countries in South Asia. Our study included only those physicians and doctors who died after contracting COVID-19 from their respective workplaces. All available data about the country of origin, type of, sex, age, medical or surgical specialty, and date of death were included.

\section{Results:}

The total number of physician deaths reported due to COVID-19 in our study was 170 , with half $(87 / 170,51 \%)$ of the deaths reported from Iran. Male physicians' death was reported to be 145 (145/170=85\%). Internal Medicine $(58,43 \%)$ was the most severely affected sub-specialty. The highest physician mortality rate in the general population recorded in Afghanistan (27/1000 deaths).

\section{Conclusion}

An increased number of physician deaths, owing to COVID-19, is seen in South Asia. This could be due to decreased personal protective equipment and the poor health care management systems of the countries in the region to combat the pandemic. Future studies should provide a detailed account of characteristics associated with physician mortalities along with the main complications arising due to the virus.

\section{Background:}

According to 2018 statistics, the Physician Density (per 10,000) of the respective countries in South Asia is; 10 medical doctors per 10,000 in Pakistan, 6 medical doctors per 10,000 in Bangladesh, 9 medical doctors per 10,000 in India, 10 medical doctOrs per 10,000 in Sri Lanka, 16 medical doctors per 10,000 in Iran and 46 medical doctors per 10,000 in the Maldives(1).

Doctors in South Asia face innumerable challenges. Bangladesh, India, Nepal, Pakistan, and Sri Lanka, which constitute a quarter of the world's population, have an insufficient investment in facilities and low precedence for specialty(2). Moreover, low life expectancy, high rates of malnourishment coupled with infant mortality, the incidence of Tuberculosis and Human Immunodeficiency Virus / Acquired Immunodeficiency Syndrome 
(HIV/AIDS) along with, poor sanitation, maternal health, and access to healthcare services, pose a significant

health challenge(3). Resource constraints are one of the important barriers to quality healthcare in addition to mal-governance, negligence, and unaccountability(1).

South Asian region faces a tough battle in the face of the COVID-19 pandemic and it is indeed hardest for regions like Africa and South Asia to prevent further deterioration of the healthcare system caused by the virus(4). The highly contagious nature of the virus places physicians on the front-line at a high risk of contracting the infection. Evidently, during outbreaks of infectious diseases, the Health Care Community faces the maximum disadvantage(5). As airway interventions for many COVID-19 patients generate aerosol, physicians are particularly at increased risk of contracting the illness (6). Moreover, Personal Protective Equipment (PPE) at all times is highly necessary and its scarcity threatens the safety of physicians working in close contact with infected patients or other co-workers (6).

The first doctor to warn the authorities' of SARS-like illness died treating COVID-19 patients in Wuhan, China(7). Thereafter, many physician fatalities were reported from China and other countries affected by the pandemic(8). This raises the question of whether and to what extent does occupational exposure to COVID-19 contribute to physicians' mortality(9). Investigations of risks associated with occupational health make an integral component of occupational safety and health management(10).Accordingly, we conducted this commentary keeping the following aims and objectives in our mind:

I. To provide an up to date and detailed account of physician deaths in South Asia during the COVID-19 pandemic.

II. To analyze and compare the different characteristics associated with physician mortality amongst the different countries of the region.

\section{Methodology:}

\section{Data Collection:}

Strengthening the Reporting of Observational Studies in Epidemiology (STROBE) guidelines was utilized to construct our manuscript(11). An Institutional Review Board approval was not needed for our review study since the evaluated data was publicly available. We performed a study based on reviewing the literature concerning the death of doctors and physicians due to COVID-19, using published news reports on their respective newspaper agencies' websites. The collected data in our study is accurate as of August $31^{\text {st, }} 2020$. This methodology of data collection concerning physician mortality has been previously validated $(10,12)$.

We selected the following 9 countries in Southern Asia regions based on the United Nations statistics division(13); Afghanistan, Bangladesh, Bhutan, India, Iran, Maldives, Nepal, Pakistan, Sri Lanka. Our Google search included keywords, 'Physician', 'doctor', 'COVID-19', 'Coronavirus', 'die', 'death' using Google in English, and was performed on June 12, 2020. The first 100 web pages, excluding the advertisement area, were used for further evaluation. Also, different news reports that were published in local languages of the respective countries were searched by the same keywords and translated using 'Google Translate'. Official institutional 
websites or social media portals (i.e., Linkedln, ResearchGate, and Twitter) were also cross-checked by writing the doctor's name to ensure no data is being missed.

Two independent investigators (E.S and S.A.) extracted data and their lists were compared to ensure accuracy of data. A third investigator (S.A.F) was consulted to resolve any inconsistency.

II. Inclusion and Exclusion Criteria:

Our study included only those physicians who died after contracting COVID-19 from their respective workplaces. The level of graduate medical education was not a criterion of inclusion in our study and thus we included reports of deaths ranging from Medical Interns to senior Consultant Physicians. Retired physicians and doctors who were working remotely from their homes and died from COVID-19 during this pandemic were excluded. The words 'doctor' and 'physician' have been used interchangeably in our study.

\section{Study Variables:}

Data about the country of origin, type of practice (private or public practice), sex, age, specialty (based on the description in the original news outlet source), and date of death were included, if available. Public practice was defined as hospitals that were functioning under government or military administration whereas private practice was defined as hospitals or clinics that were functioning autonomously. If the physician's name was reported but the sex was not mentioned, then attempts were made to identify the gender using an online tool(14). Duplicated reports were aggregated by cross-checking the names of medical doctors.

\section{Statistical Analysis:}

The extracted data was arranged on a Microsoft Excel spreadsheet (Version 15.37, Microsoft Corporation, Redmond, WA) using a standardized data collection tool. Data were analyzed utilizing SPSS version 23 (IBM SPSS Statistics, IBM Corporation, Armonk, New York).

\section{Results:}

\section{i. Study Characteristics:}

The total number of physician deaths reported due to COVID-19 was 170 . The date of reported deaths in our study ranged from 6th March 2020 to 21th July 2020.

The number of men reported dead was 145 (85\%). Sex information was not available for 13 (8\%) physicians. The median age of physicians in our study was 60 years (Inter-Quartile Range $=14$ ). The median age of men was 60 years whereas that of women was 53 years. The age information of 121 physicians was not available. Half of the deaths reported in our study were Iran, followed by Pakistan $(26 / 170=15 \%)$ and India $(25 / 170=$ $15 \%)$ as shown in Fig. 1. The reported physician deaths in Sri Lanka, Bhutan, Nepal, and the Maldives were none. The physician specialties with the most number of physician deaths were Internal Medicine (58/135= $43 \%)$, Pediatrics $(12 / 135=9 \%)$, and Anesthesiology $(11 / 135=8 \%)$. Proportionally, every seven out of ten doctors $(99 / 135=73 \%)$, that died due to COVID-19, belonged to an Internal Medicine specialty. 


\section{ii. Country-based Analysis of Study Variables:}

The country with the lowest median age of physicians at the time of death was Pakistan (52) closely followed by Iran (53) as shown in Table 1. Iran recorded the highest number (81) and proportion (56\%) of deaths amongst men. Out of the 5 deaths of Medical Interns reported in our study, $4(80 \%)$ were reported from Pakistan. General Surgeon fatality number (7) and proportion (78\%) were highest in Iran. The majority of the deaths in India (72\%) and Bangladesh (58\%) were reported in physicians who practiced in a private setup. However, the majority of physicians in Pakistan (69\%) were affiliated with public-sector hospitals. In our study, the mean mortality rate was calculated to be 7 physician deaths per 1000 deaths among the general population. Country-wise, the highest physician mortality rate per 1000 deaths in the general population was recorded in Afghanistan (27), followed by Bangladesh (16) and Iran (10). Table 1 breaks down these study variables based on the available data from countries of South Asia.

\section{Discussion:}

Our study reports increasing numbers of deaths in physicians from COVID-19 in South Asia. The poor health care management systems, in comparison to developed countries like the USA(15), of most of the countries and extreme shortage and hoarding of PPEs in the region might be the major contributing factors which put physicians at a greater threat of death from the disease(15-17). Common findings to all South Asian countries included a greater proportion of deaths of Internal Medicine specialists and male physicians. This could be because internal medicine specialists play a significant role at the frontline by offering patientcentered care(18) and male sex is associated with severe complications of COVID-19(19). Increased age is one of the risk factors for the complications of COVID-19(19). The median age of physician mortality in our study was 60 years. These findings were parallel to those reported by E B Ing et al., reporting significant physician mortality due to the disease(10). E Kursumovic et al. also analyzed extensive data of Health Care Workers' (HCWs) deaths due to COVID-19 which concluded that HCWs are at risk of contracting COVID-19 through their occupational exposure (8). Previously, epidemiological studies carried out in South Asia have linked communicable diseases with increased mortality in HCW's (20).

Iran reported the highest proportion of physician deaths in our study and this has been previously reported by E B Ing et al. where they concluded Iran to have the second-highest physician mortality in the world as of May 2020. In March 2020, Iran became one of the epicenters of the infection(21) and there are many reasons why the country faces a relatively difficult situation(21-23). Over the past 4 decades, Iran has tried to implement various methods to improve its health care system, however, many barriers are preventing the actual implementations of these reforms(24). In contrast, up to date numbers of physician mortality in the USA, with the highest number of total cases in the world, is only 27 (22). This highlights that a robust and competent health-care management system could play a major role in mitigating the effects of communicable diseases on the front-line HCW's.

Although much of the findings are similar amongst the major countries of South Asia, individual characteristics are worthy of mention. The mortality rate in India per 1000 in the general population was the lowest amongst all countries. Even though COVID-19 presents as a tough battle due to the scarce healthcare resources in the country (25), the Indian government continues to assure that the provision of PPE will be their 
priority. Moreover, ordinances against physician violence have been issued that commit to protecting HCWs $(26,27)$. Afghanistan faces a rather arduous battle with COVID-19 where since the early 1970s, civil war has left a poor healthcare system in the country, and domestic conflicts and social taboos during the pandemic further complicate the situation(25) This is further highlighted as in our study the highest physician mortality rate per 1000 deaths in the general population was recorded from Afghanistan and still, concerns of low testing rate, inadequate reporting, and asymptomatic cases increase the suspicion of under-reporting of deaths(28).

The majority of the deaths of medical interns were reported from Pakistan with the median age of mortality being the lowest amongst all countries of the region. This could be mainly because young physicians like medical interns are perceived as first-line service providers in hospitals of the country(29). Long shift hours during an intern year and vulnerability to the increased influx of infected patients could be a crucial factor attributed to the increased number of deaths in these individuals (30). Pakistan also reported an increased number of physicians' deaths who were affiliated with the public sector hospitals. This may well suggest that Pakistan's public health care system has not been equipped enough to meet the demands of the pandemic.

Our study highlights that many countries in South Asia reported considerable number of deaths due to COVID19 with a high mean physician mortality rate. One of the major contributory factors remains the lack of PPE and the economic burden that confines nations from implementing ways to stop further physician deaths. Nevertheless, it could be very likely for these figures to increase as the second wave has already hit majority of South Asia. Ways to prevent the misuse, hoarding, and black-marketing of PPE are strongly recommended. An overhaul of the entire healthcare infrastructure and management is needed in the region to tackle the current and any prospective epidemic or pandemic that may arise. It is crucial that international organizations such as World Health Organization, World Bank, United Nation Development Programme, Doctors without Borders, etc. and respective national policy-making organizations collectively collaborate to help alleviate the crisis that these countries of the region face.

\section{Conclusion:}

Our study aims to highlight how the COVID-19 pandemic is affecting the healthcare workforce in the region as we spotlight increased physician mortality numbers from South Asia. The reasons can be majorly attributed to decreased PPE, the highly infectious nature of the virus added to the poor health care management systems of the countries in the region to combat the pandemic. The highest number of physician deaths in the region were recorded in Iran whereas physician mortality characteristics show an increased number of deaths of internal medicine specialists and men. Future studies should be aimed to provide a further account of the detailed characteristics such as individual co-morbidities, socio-economic status, and main complications arising due to COVID-19 infection in physicians.

\section{Limitations}

In our study, data on physician mortality numbers and characteristics were collected from newspaper websites and other online reporting sources. This leads to a possibility of the number of physicians' deaths and other study variables such as age being under-reported. Similarly, although reported physician deaths 
from Sri Lanka, Nepal, and the Maldives were none, there is a possibility of physician deaths in these countries that were not reported by mainstream news outlets. The rapidly changing figures of the pandemic, low diagnostic testing and reporting rates, and unavailability of government-provided data from each country should be considered. Therefore, our study data is accurate as of August 31st, 2020.

\section{Declarations}

Ethical Approval and Consent to Participate: All data collected and analyzed in this study is publically available therefore ethical approval and consent to participate was not needed for this study.

\section{Author Contribution:}

NNJ (Guarantor): conduct, literature search, manuscript preparation, manuscript editing, and manuscript review, final approval, and agreeing to the accuracy of the work

SA (Guarantor): conduct, literature search, manuscript preparation, manuscript editing, and manuscript review, final approval, and agreeing to the accuracy of the work

ES (Guarantor): conduct, data acquisition, data analysis, statistical analysis, manuscript preparation, manuscript editing and manuscript, final approval, and agreeing to the accuracy of the work

SAF (Guarantor): planning, conduct, data acquisition, data analysis, statistical analysis, manuscript editing, and manuscript review, final approval and agreeing to the accuracy of the work

KF (Guarantor): planning, conduct, manuscript preparation, manuscript editing and manuscript review, final approval, and agreeing to the accuracy of the work

SFM (Guarantor): planning, conduct, manuscript preparation, manuscript editing and manuscript review, final approval, and agreeing to the accuracy of the work

Competing Interest Statement: The authors have no relevant disclosures. All authors had access to all the study data, take responsibility for the accuracy of the analysis, and had authority over manuscript preparation and the decision to submit the manuscript for publication. The manuscript represents original work that has not been published and is not under consideration for publication in any other journal. All authors meet the criteria for authorship and instructions to the author were read. We accept all conditions and publication rights.

Funding: This research did not receive any specific grant from funding agencies in the public, commercial, or not-for-profit sectors.

Declaration of Interests: None

Acknowledgements: None

Availability of Data and Materials: The datasets used and/or analyzed during the current study are available from the corresponding author on reasonable request. 


\section{References}

1. Khalid F, Abbasi AN. Challenges Faced by Pakistani Healthcare System: Clinician's Perspective. J Coll Physicians Surg Pak. 2018 Dec;28(12):899-901.

2. van Weel C, Kassai R, Qidwai W, Kumar R, Bala K, Prasad Gupta P, et al. Primary healthcare policy implementation in South Asia. BMJ Glob Heal. 2016 Sep;1(2):e000057.

3. Simon A, Bhumika T, Jaswal R, Nair S. Public Health Priorities of South Asia: An Overview. Int J Adv Res. 2015 Apr;3:424-8.

4. Bhandari DJ. South Asian countries cannot make the same choices as developed nations [Internet]. South Asia Monitor. 2020 [cited 2020 Aug 2]. Available from:

https://southasiamonitor.org/spotlight/south-asian-countries-cannot-make-same-choices-developednations

5. Sepkowitz KA, Eisenberg L. Occupational Deaths among Healthcare Workers. Emerg Infect Dis J. 2005;11(7):1003.

6. Spinazzè A, Cattaneo A, Cavallo DM. COVID-19 outbreak in Italy: protecting worker health and the response of the Italian Industrial Hygienists Association. Ann Work Expo Heal. 2020 Apr;wxaa044.

7. Misra A. Doctors and healthcare workers at frontline of COVID 19 epidemic: Admiration, a pat on the back, and need for extreme caution. Diabetes Metab Syndr. 2020;14(3):255-6.

8. Kursumovic E, Lennane S, Cook TM. Deaths in healthcare workers due to COVID-19: the need for robust data and analysis. Vol. 75, Anaesthesia. John Wiley \& Sons, Ltd; 2020. p. 989-92.

9. Agius RM. Doctors' deaths from covid-19 should be reported to the coroner. Vol. 369, The BMJ. 2020. p. m1622.

10. Ing EB, Xu Q (A), Salimi A, Torun N. Physician deaths from corona virus (COVID-19) disease. Occup Med (Chic III). 2020 May;70(5):370-4.

11. von Elm E, Altman DG, Egger M, Pocock SJ, Gøtzsche PC, Vandenbroucke JP. The Strengthening the Reporting of Observational Studies in Epidemiology (STROBE) statement: guidelines for reporting observational studies. J Clin Epidemiol. 2008 Apr;61(4):344-9.

12. Yoshida I, Tanimoto T, Schiever N, Patelli F, Kami M. Characteristics of doctors' fatality due to COVID-19 in Western Europe and Asia-Pacific countries. QJM. 2020 May;113(10):713-4.

13. UNSD. UNSD - Standard country or area codes for statistical use (M49) [Internet]. 25. United Nations Statistics Division- Standard Country and Area Codes Classifications (M49). 2016 [cited 2020 Aug 3]. p. 275. Available from: https://unstats.un.org/unsd/methodology/m49/

14. Peters G. Baby Name Guesser. [cited 2020 Aug 3]; Available from: www.gpeters.com/names/babynames.php

15. Javed B, Sarwer A, Soto EB, Mashwani Z-U-R. Is Pakistan on track to have COVID-19 transmission and mortality rates similar to those of Italy, Iran or the USA? Drugs Ther Perspect Ration drug Sel use. 2020 Apr;1-5.

16. Exhausted Iranian healthcare workers at risk. Financial Times [Internet]. Available from: ft.com/content/9418125e-6839-11ea-800d-da70cff6e4d3 
17. Anwar S, Nasrullah M, Hosen MJ. COVID-19 and Bangladesh: Challenges and How to Address Them. Front Public Heal. 2020;8:154.

18. Lee A. General practitioners as frontiers in COVID-19: The Hong Kong experience. Aust J Gen Pract. 2020 Apr;49.

19. Jin JM, Bai P, He W, Wu F, Liu XF, Han DM, et al. Gender Differences in Patients With COVID-19: Focus on Severity and Mortality. Front Public Heal. 2020;8:152.

20. Basavaraj A, Chandanwale A, Patil A, Kadam D, Joshi S, Gupte N, et al. Tuberculosis risk among medical trainees, Pune, India. Emerg Infect Dis. 2016 Mar;22(3):541-3.

21. Behzadifar M, Ghanbari MK, Bakhtiari A, Behzadifar M, Bragazzi NL. Ensuring adequate health financing to prevent and control the COVID-19 in Iran. Int J Equity Health. 2020 May;19(1):61.

22. Murphy A, Abdi Z, Harirchi I, McKee M, Ahmadnezhad E. Economic sanctions and Iran's capacity to respond to COVID-19. Lancet Public Heal. 2020/04/06. 2020 May;5(5):e254-e254.

23. Takian A, Raoofi A, Kazempour-Ardebili S. COVID-19 battle during the toughest sanctions against Iran. Vol. 395, The Lancet. 2020. p. 1035-6.

24. Sajadi HS, Ehsani-Chimeh E, Majdzadeh R. Response to: Letter to the Editor "Universal Health Coverage in Iran: Where we stand and how we can move forward." Vol. 33, Medical Journal of the Islamic Republic of Iran. Iran University of Medical Sciences; 2019. p. 9.

25. Chatterjee K, Chatterjee K, Kumar A, Shankar S. Healthcare impact of COVID-19 epidemic in India: A stochastic mathematical model. Med J Armed Forces India. 2020 Apr;76(2):147-55.

26. Covid-19: Indian government vows to protect healthcare workers from violence amid rising cases. BMJ. 2020 Apr;369:m1631.

27. Pleased with India's steps to protect healthcare workers combating COVID-19: Alice Wells. ANI South Asia's leading News Agency [Internet]. Available from: https://www.aninews.in/news/world/us/pleasedwith-indias-steps-to-protect-healthcare-workers-combating-covid-19-alice-wells20200425065820/

28. Azizy A, Fayaz M, Agirbasli M. Do Not Forget Afghanistan in Times of COVID-19: Telemedicine and the Internet of Things to Strengthen Planetary Health Systems. Omi A J Integr Biol. 2020 Apr;24(6):311-3.

29. Hassan M, Hussain T, Ahmed SM, Fraz TR, Rehmat Z. Perceived stress and stressors among house officers. Indian J Occup Environ Med. 2014;18(3):145-9.

30. The Guardian. Pakistan arrests doctors protesting over lack of virus safety equipment. The Guardian [Internet]. 2020; Available from: https://www.theguardian.com/world/2020/apr/06/pakistan-arrestsdoctors-protest-lack-coronavirus-safety-equipment

\section{Tables}


Table 1: Breakdown of Study Variables based on Country of Origin

$\begin{array}{lllllll}\text { Study Variables } & \text { India } & \text { Pakistan } & \text { Iran } & \text { Bangladesh } & \text { Afghanistan } & \begin{array}{c}\text { Total } \\ \mathrm{n}=170\end{array} \\ & \begin{array}{llll}\mathrm{n}=25 \\ (15 \%)\end{array} & \mathrm{n}=26 & \mathrm{n}=87 & \mathrm{n}=19 & \mathrm{n}=13 & (100 \%) \\ & & (15 \%) & (51 \%) & (11 \%) & (8 \%) & \end{array}$

\section{Gender}

Males

22

(88\%)

Females

N/A

\section{Physician Specialty}

Anesthesiologist

Cardiologist

Pulmonary and Critical

Care Specialist

Dermatologist

Otolaryngologists

General Physician

Gynecologist/Obstetrician

Hematologist/Oncologist

Infectious Disease

Specialist

Medical Officer/House

Officer

Neurologist

Ophthalmologist

Orthopedic Surgeon

Pediatrician

Pathologist

Psychiatrist

Radiologist

General Surgeon

N/A

Type of Practice

\begin{tabular}{llllll}
$0(0 \%)$ & $4(7 \%)$ & $6(15 \%)$ & $2(10.5 \%)$ & $0(0 \%)$ & $12(7 \%)$ \\
\hline $3(12 \%)$ & $0(0 \%)$ & $0(0 \%)$ & $1(5 \%)$ & $9(69 \%)$ & $13(8 \%)$
\end{tabular}

$145(85 \%)$

$22(85 \%) \quad 81(93 \%) \quad 16(84 \%) \quad 4(31 \%)$

$11(6.5 \%)$

$0(0 \%) \quad 3(11.5 \%) \quad 5(6 \%) \quad 3(16 \%) \quad 0(0 \%)$

$1(1 \%)$

$0(0 \%) \quad 1(4 \%) \quad 0(0 \%) \quad 0(0 \%)$

$0(0 \%)$

$9(5 \%)$

$1(4 \%) \quad 2(8 \%) \quad 5(6 \%) \quad 1(5 \%)$

$0(0 \%)$

2(1\%)

$0(0 \%) \quad 1(4 \%) \quad 1(1 \%) \quad 0(\%)$

$0(\%)$

$3(2 \%)$

$0(0 \%) \quad 1(4 \%)$

$2(2 \%) \quad 0(0 \%)$

$0(0 \%)$

$58(34 \%)$

$11(44 \%) \quad 8(31 \%) \quad 34(39 \%) \quad 3(16 \%)$

$2(15 \%)$

$5(3 \%)$

$0(0 \%) \quad 1(4 \%)$

$2(2 \%) \quad 2(10.5 \%)$

$0(0 \%)$

$2(1 \%)$

$2(2 \%) \quad 0(0 \%)$

$0(0 \%)$

$1(1 \%)$

$0(0 \%) \quad 0(0 \%)$

$1(1 \%) \quad 0(0 \%)$

$0(0 \%)$

$0(0 \%)$

$5(3 \%)$

$0(0 \%) \quad 4(15 \%) \quad 0(0 \%) \quad 1(5 \%)$

$0(0 \%)$

$0(0 \%)$

$1(1 \%)$

$1(4 \%) \quad 0(0 \%)$

$0(0 \%)$

$0(0 \%)$

$0(0 \%)$

$2(1 \%)$

$3(12 \%) \quad 0(0 \%)$

$2(2 \%)$

$2(10.5 \%)$

$0(0 \%)$

$6(3.5 \%)$

$0(0 \%) \quad 2(8 \%) \quad 8(9 \%) \quad 1(5 \%)$

$1(8 \%)$

$12(7 \%)$

$0(0 \%) \quad 2(8 \%) \quad 1(1 \%) \quad 1(5 \%)$

$0(0 \%)$

$4(2 \%)$

$0(0 \%) \quad 0(0 \%) \quad 3(3 \%) \quad 0(0 \%)$

$0(0 \%)$

$3(2 \%)$

$0(0 \%) \quad 0(0 \%) \quad 0(0 \%) \quad 1(5 \%)$

$0(0 \%)$

$1(1 \%)$

$0(0 \%) \quad 1(4 \%)$

$7(8 \%) \quad 0(0 \%)$

$1(8 \%)$

$9(5 \%)$

$9(36 \%) \quad 0(0 \%)$

$13(15 \%) \quad 4(21 \%)$

$9(69 \%)$

$35(21 \%)$ 


\begin{tabular}{|lllllll|}
\hline Public & $3(12 \%)$ & $18(69 \%)$ & $4(5 \%)$ & $5(26 \%)$ & $3(23 \%)$ & $33(19 \%)$ \\
\hline Private & $18(72 \%)$ & $7(27 \%)$ & $14(16 \%)$ & $11(58 \%)$ & $1(8 \%)$ & $51(30 \%)$ \\
\hline N/A & $4(16 \%)$ & $1(4 \%)$ & $69(79 \%)$ & $3(16 \%)$ & $9(69 \%)$ & $86(51 \%)$ \\
\hline Mortality Rate & & & & & & \\
\hline Per 1000 deaths & 2.5 & 9 & 10 & 16 & 27 & 7 \\
\hline
\end{tabular}

\section{Figures}

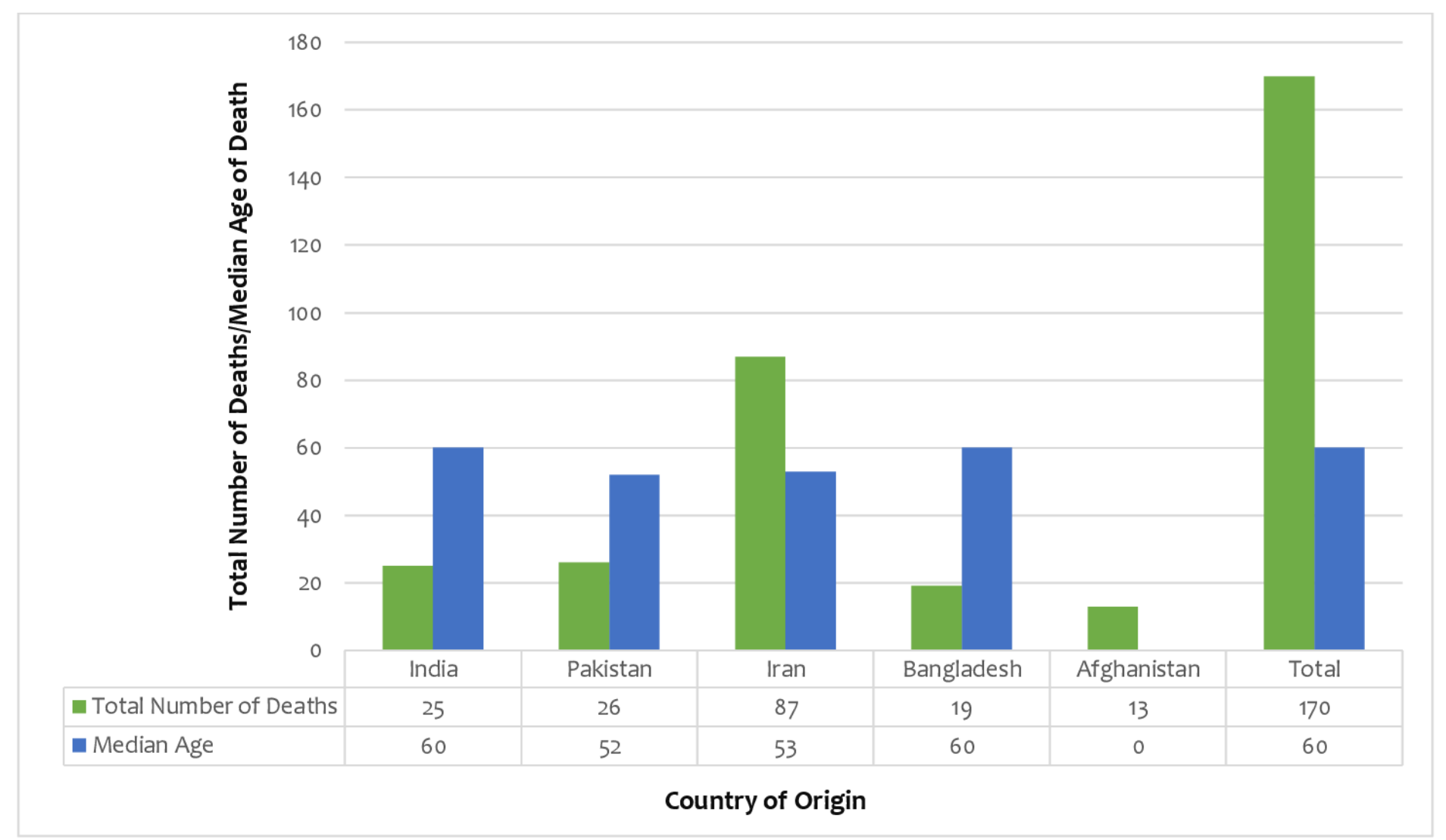

\section{Figure 1}

Relationship between country of origin with total number of deaths and median age of death. Bars illustrate the total number of deaths and median age at the time of death of all physicians according to their country of origin as well as a cumulative total of all countries. 